\section{Effect of Adrenalectomy on Histamine Metabolism in the Rat}

THE effect of adrenalectomy on the metabolism of histamine in the rat has been investigated by several workers, but with conflicting results. Though it has been established that after adrenalectomy the histamine con. tents of some rat tissues are raised $\mathbf{1}^{\mathbf{1 - 4}}$, there is considerable discrepancy regarding how the rise is brought about and the conditions under which it occurs. For example, increased levels of tissue histamine in adrenalectomized rats have been attributed by different workers to: (I) increased uptake of histamine from the gut ${ }^{2} ;(2)$ increased rate of tissue histamine formation ${ }^{5}$; (3) increased ability of tissues to bind histamine ${ }^{4}$; (4) decreased activity of histaminase ${ }^{1}$. Some workers have reported that the increases in histamine-levels after adrenalectomy are greater if the animals are given water to drink than if they are given saline ${ }^{1}$, while others have found that in animals given saline increases in the tissue levels of this amine do not occur ${ }^{3}$.

The present experiments were performed in the hope of clarifying these discrepancies. Groups of 6 female rats of Wistar strain (120-180 g) were bilaterally adrenalectomized under ether anæsthesia. The animals received their normal food and either 0.9 per cent saline or drinking water, and were killed 4,14 or 49 days after the operation. The histamine contents of various tissues were determined by the method of Parratt and West ${ }^{6}$. The results, each of which is the mean of the values from at least 3 experiments, are presented in Table 1 .

Table 1. EFfect of AdRenalectomy on the Histamine Content of

\begin{tabular}{l}
\multicolumn{1}{c}{ Tissue } \\
Abdominal skin \\
Skin of the feet \\
Ears \\
Fundic stomach \\
Pyloric stomach \\
Jejunum \\
Ileum \\
Colon \\
Liver \\
Kidney \\
Lung
\end{tabular}

\begin{tabular}{cc}
\multicolumn{2}{c}{ RAT Tissuks } \\
Water & Saline \\
4 days & 4 days \\
256 & 158 \\
281 & 173 \\
278 & 139 \\
249 & 180 \\
333 & 239 \\
220 & 156 \\
267 & 136 \\
275 & 182 \\
340 & 260 \\
406 & 271 \\
285 & 162
\end{tabular}

Saline
14 days
238
205
251
300
320
201
202
229
240
325
300

Saline
49 days
147
128
114
144
120
121
127
98
94
113
100

The animais reccived their normal food and either saline or drinking water, and were killed 4, 14 or 49 days after the operation. All values are or mock-adrenalectomized rats.

The results demonstrate two points. First, the increases in tissue histamine after adrenalectomy are as great in the skin and some other tissues as in the alimentary eanal; the findings of some authors that major increases in histamine-levels are confined to the gastro-intestinal tract could not be confirmed ${ }^{1,2,4}$. Secondly, the increases are of similar magnitude in rats maintained on water and in rats maintained on saline. In rats maintained on water, the histamine contents of the tissues reach their highest values 4 days after the operation; in rats maintained on saline the values are highest 10-15 days after the operation and do not return to pre-adrenalectomy levels until 5-6 weeks later.

In a further series of experiments, the daily urinary excretion of histamine ( $\mu \mathrm{g}$ free histamine/100 $\mathrm{g}$ body. weight/18 h) was followed before and after removal of the adrenals. No significant changes were noted, either in animals drinking water or in animals drinking saline. This result is in contrast with that of Bjurö and Westling, who have reported a two-fold increase in the excretion of histamine in adrenalectomized rats maintained on saline ${ }^{5}$. In the present work, however, the rats did not receive aminoguanidine to inhibit histaminase. The excretion of histamine was also measured in non-operated rats receiving cortisone, prednisolone or deoxycortone acetate $(10 \mathrm{mg} / \mathrm{kg}$ daily for 9 days), and again no changes were noted.

Injections of glucocorticoids reduce the histamine content of the skin and small intestine, but increase tho content of this amine in the pyloric stomachi. As is shown in Table 1, adrenalectomy likewise increases the histamine content of the pyloric stomach. While the changes in histamine-levels after glucocorticoids are probably due to changes in the rate of histamine formation $^{8}$, little or no alterations occur in the histamine. forming capacities of rat tissues after adrenalectomy. Thus, the histidine decarboxylase activities of the liver and pyloric stomach, the two major sources of this enzyme in the adult rat ${ }^{8}$, are unaffected by adrenalectomy ${ }^{9,10}$. Schayer et al. have reported increases in the histiding decarboxylase activity of the skin and lung of adrenalectomized rats ${ }^{11}$, but such increases are unlikely to account for the major and rapid changes in histamine-levels since these tissues contain only minute amounts of the enzyme. and are capable of forming only very small quantities of histamine.

It is more probable that the levels of tissue histamine are raised in the absence of the adrenals because of increased firmness in the binding of the amine to tissue components, coupled with a reduction in histaminase activity. It is known that after adrenalectomy the activity of this enzyme in the rat is reduced ${ }^{8,12}$. A final series of experiments showed that inhibition of histaminase activity is greater when the rats are maintained on water than when they are maintained on saline; it is possible that this latter finding accounts for the increases in the levels of tissue histamine occurring more rapidly in rats maintained on water.

Department of Physiology,

University of the West Indies, Kingston 7 , Jamaica.

${ }^{1}$ Rose, B., and Browne, J. S. L., Amer. J. Physiol., 131, 589 (1941).

2 Marshall, P. B., J. Physiol., 102, 180 (1943).

${ }^{3}$ Hicks, R., and West, G. B., Nature, 182, 401 (1958).

${ }^{4}$ Bartlett, A. L., and Lockett, M. F., J. Physiol., 147, 51 (1959)

${ }^{5}$ Bjurö, T., and Westling, H., Nature, 184, 1241 (1959).

${ }^{6}$ Parratt, J. R., and West, G. B., J. Physiol., 137, 169 (1957).

'Telford, J. M., and West, G. B., Brit. J. Pharmacol., 15, 532 (1960).

'Telford, J. M., and West, G. B., J. Pharm. (Lond.), 13, 75 (1961).

- Telford, J. M., and West, G. B., Brit. J. Pharmacol., 16, 360 (1961).

${ }^{10}$ Schayer, R. W., Amer. J. Physiol., 189, 533 (1957).

${ }^{11}$ Schayer, R. W., Smiley, R. L., and Davis, K. J., Amer. J. Physíot, 18\%, $63(1956)$.

${ }^{22}$ Karady, S., Rose, B., and Browne, J. S. T., Amer. J. Physion, 130, 539) $(1940)$.

\section{Influence of Pregnancy and an Oxidized Lipid Diet on the Fatty Acid Composition of Blood and Tissues}

RECENTLY it has been shown that a diet which is low in vitamin $\mathrm{E}$ and which contains 5 per cont of oxidized lipid is capable of producing the generalized Shwartzman reaction in pregnant rats ${ }^{1,2}$. This reaction is characterized by an episode of disseminated intravascular coagulation and, in the past, has only been produced experimentally by intravenous injection of bacterial endotoxin. The fact that the only variant in the diet which was responsible for its lethal effect was the oxidized lipid plus the fact that an increase in stainable lipid could be demonstrated in the kidney, liver, and placentas of some animals led to an investigation of the distribution of fatty acids in the blood. and tissues of these animals. It seemed appropriate to compare the fatty acid compositions of tissue lipids of pregnant and non-pregnant female rats fed the oxidized lipid diet (20 per cent casein, 61 per cent corn starch, 10 per cont brewers' yeast, 4 per cent salt mixture, and 5 per cent of the ethyl esters of a molecularly distilled fraction of oxidized cod liver oil) with those of similar rats fod a pellet stock diet containing approximately 5 per cont fat.

The rats were killed on the last day of pregnancy (or 2 lst day of experiment for the non-pregnant controls), and lipids were extracted from sorum, perirenal fat. Iivor, 